\title{
Towards a Global Approach to Reinsurance Regulation
}

\author{
Ralph Vogelgesang and Matthias Kubicek \\ Munich Re Group, Group Legal, Koniginstraße 107, 80802 Munchen, Germany. \\ E-mails: rvogelgesang@munichre.com, mkubicek@munichre.com
}

The article examines how supervisory rules and other regulations (can) restrict or impede reinsurers' access to the insurance markets. The authors make a plea for an international supervisory regime for reinsurance companies, which could be achieved through bilateral agreements between countries. Special provisions in free-trade and partnership agreements could also play a role.

The Geneva Papers (2007) 32, 413-425. doi:10.1057/palgrave.gpp.2510136

Keywords: reinsurance; reinsurance directive; market access; mutual recognition; group supervisor; Solvency II

\section{Introduction}

Reinsurance companies' business models are based on the widest possible distribution of risks (economies of scale) and the exploitation of diversification effects (economies of scope). They can only benefit from these economies by writing a large number of diversified risks in as many markets as possible. It is therefore crucial for companies with adequate expertise, appropriate risk-management tools and capital commensurate with the risks they assume, to enjoy unrestricted worldwide access to markets, freedom of contract and complete fungibility of capital. In other words, professionally managed and well-capitalised reinsurance companies should be able to operate freely. Nor should supervisory rules limit this freedom more than is necessary. On the contrary, the eligibility of reinsurers to conduct business should be established by a (single) body and effectively monitored on a day-to-day basis. State supervisory regimes should be compatible with each other, create a level playing field for market players and prevent regulatory arbitrage. We examine below the current situation in regions of major commercial importance in the world and consider what needs to be done in the area of supervisory regulations.

\section{Current situation}

Supervision following the Reinsurance Directive ${ }^{1}$

Creation of a single European market

Preparations in the EU and the European Economic Area (EEA) are well advanced. After years of consultations, the Reinsurance Directive (RID) came into force at the

\footnotetext{
${ }^{1}$ EU Council of Ministers (2005).
} 
beginning of December 2005. ${ }^{2}$ EU member states have until the end of 2007 to translate the Directive into national law. In Germany, the 2004 amendment to the Insurance Control Act had already implemented the vast majority of the regulations, and the 2006 amendment to the Act, which is expected to come into force in spring/ summer 2007, will implement the remaining provisions. These include regulations for finite reinsurance and special-purpose vehicles and, importantly, rules governing the treatment of third-country reinsurers. Thus, in implementing the RID, German Law will for the first time introduce rules for the treatment of third-country reinsurers.

The Directive will create a single market for reinsurers and reinsurance services in the EU (and the EEA), based on the principles the EU has been observing for decades when drafting regulations to be applied throughout Europe, that is, minimum harmonisation of certain fundamental rules across member states ${ }^{3}$ with mutual recognition of regulations in force in individual member states.

As regards reinsurance, this means that the supervisory rules applicable in the country in which the head office of a reinsurance company is situated are (mutually) recognised by the other member states, that is to say, a reinsurer's licence to operate in one member state is valid throughout Europe. The authorities of the country in which its head office is situated are responsible for supervision (home-country principle).

Thus, an immediate benefit from the single market created by the RID is that reinsurers require only a single licence to operate throughout Europe, so that the licence is valid in all 30 EEA countries. ${ }^{4}$ Evidently, this will simplify administration and increase efficiency at the companies concerned.

The granting of a licence to a company in its home country entitles it to conduct reinsurance business both in that country of course, and in the other member states, through both cross-border activity out of the home country and branches situated in those states. In practice, this will have far-reaching consequences. Instead of being supervised by the authorities of the countries in which they are situated as in the past, branches will in future be subject to supervision by the regulator in the parent company's home country (home supervisor). Furthermore, as branches in other EU countries are not separate legal entities, they no longer need to be separately capitalised. This is of obvious benefit for reinsurance companies as regards risk diversification, fungibility of capital and capital requirements as a whole. In short, reinsurers will be in the position enjoyed by insurers since implementation of the third generation of EU directives in 1994. However, the new level of harmonisation is of greater relevance for reinsurance companies, as they are less dependent than primary insurers on gaining access to the business-to-business market via subsidiaries (which continue to be regulated in their own home country). This is because, in primary insurance, the "all business is local" principle is widely applicable, and proximity to the customer is particularly important to success.

\footnotetext{
2 Evans (2007).

${ }^{3}$ Following attempts at harmonisation over many years, the EU has recognised that a maximum level of harmonisation, that is, the complete harmonisation of member-state regulations in a particular area, takes too long. It is sufficient to bring into line the most important aspects of legislation in member states, thus enabling countries to "mutually recognise" each other's regulations.

${ }^{4}$ EU plus Norway, Iceland and Liechtenstein.
} 
A further major benefit of the single market created by the RID is the removal of legally prescribed deposit requirements, to be implemented by the end of 2008 . Of course, insurers and reinsurers will be free to contract to provide deposits if they so wish.

However, the single European market for reinsurers is subject to some restrictions. Basically only "financial supervision", relating to solvency margins, reserves and investments, has been harmonised and therefore mutual recognition applies only to these areas. Not included is regulation of market conduct, which continues to be supervised by the countries in which a reinsurer operates (country of occupational activity principle). Also, the supervision responsibilities remaining with the country in which a reinsurer is operating may include "fit and proper" control of senior management and shareholder control.

Supervision of third-country reinsurance companies following implementation of the RID in Germany

The RID is not only intended to create a single European market; it also covers the relationship between the EU and third countries. In Germany, in accordance with Article 49 of the RID, the 2006 amendment to the Insurance Control Act lays down rules for the supervision of third-country reinsurers. It is clear from the regulations that their aim is to keep the German market open and to avoid any restrictions on freedom of contract. Under European Law as laid down in Article 49 of the RID, third-country reinsurance companies may not enjoy better treatment than "domestic" reinsurers. Third-country reinsurance companies are reinsurers having their head office outside the area of application of the RID, that is, outside the EEA. German Law takes account of the requirement to avoid conferring any competitive advantage by prescribing substantially equal treatment of reinsurance companies from inside and outside the EU and thus fulfils the requirement for an open marketplace and the maximum possible freedom of choice of legal form, as demanded by the international business models of reinsurers. ${ }^{5}$ Pursuant to Section $121 \mathrm{i}$ of the Insurance Control Act, third-country reinsurers will in future have two options for conducting reinsurance business in Germany, apart from establishing a subsidiary.

First, a third-country reinsurer may, with the authorisation of the BaFin, set up a branch in Germany, which is then subject to normal financial and legal supervision by the BaFin.

However, a third-country reinsurer does not have to have a branch to write reinsurance business in Germany, but may also operate in Germany out of its home country through "cross-border" business. In this respect, reinsurance supervisory law differs from that applicable to primary insurers, as a third-country primary insurer must establish a branch to gain access to the German market. However, a thirdcountry reinsurer may only transact cross-border business if (1) it is authorised to conduct reinsurance business in its home country, (2) the supervisory system in its home country satisfies international minimum requirements and (3) satisfactory

\footnotetext{
${ }^{5}$ See Introduction.
} 
cooperation with the BaFin can be guaranteed. The BaFin will therefore need to examine the supervisory systems concerned.

It is as yet not clear how other EU member states will be implementing the RID in respect of treatment of third-country reinsurance companies. In any case, the message sent by the implementation of Article 49 of the RID in Germany is that reinsurers from third countries are welcome, provided that they are subject to an internationally recognised supervisory regime in their home country. In the interests of an open marketplace, it would be desirable for other jurisdictions to follow this example.

\section{Solvency II}

Consideration will also need to be given in the context of Solvency II, the EU's new insurance supervision system, to the treatment of reinsurance companies from third countries and to whether their access to European markets should be restricted for supervisory reasons.

This area will attract more interest as the project nears its conclusion, since Solvency II will introduce complex quantitative and qualitative requirements for insurers and reinsurers in Europe. Every effort should be made to ensure that the treatment of third-country reinsurers cannot give rise to opportunities for supervisory arbitrage. The requirement to avoid conferring any competitive advantage currently contained in Article 49 of the RID is therefore, and will continue to be, absolutely justified. At the same time, access to the EU market should be sufficiently free to open up the European insurance market for the insurance capacity of third-country reinsurers and for European reinsurers to be entitled to expect liberal access to other reinsurance markets in return.

With this aim in mind, CEIOPS (Committee of European Insurance and Occupational Pensions Supervisors) proposed in Consultation Paper 16 that access to the EU market be dependent on the reinsurer's rating issued by a rating agency and on a rating by CEIOPS of the third-country supervisory system concerned.

This would actually involve market access being regulated unilaterally by the EU, which is surprising bearing in mind that Article 50 of the RID provides for the EU to be able to conclude bilateral agreements with third countries on mutual recognition of supervisory regulations (for reinsurers). Bilateral agreements certainly have the advantage over unilateral solutions that they have a binding effect on the contracting parties. The EU and the counterparty country would be legally obliged to (mutually) recognise the supervision process in a reinsurer's home country. Restricted market access due to supervisory law should then be effectively a thing of the past.

CEIOPS' justification for its proposed unilateral solution is that certain jurisdictions - by which they presumably mean the U.S.A. - do not possess a federal supervisory authority, making international agreements on supervision difficult. While this is no doubt true, it disregards two bills currently under consideration by Congress, the object of which is to allow U.S. reinsurers the option of converting from the present reinsurance supervision at individual state level to a federal supervision system. ${ }^{6}$

\footnotetext{
${ }^{6}$ See Section entitled Current Situation - collateral/regulatory reform in the U.S.A.
} 
A further drawback of the CEIOPS proposal could be that it relies on rating agencies, which do not use the same methods as supervisory authorities. It is worth considering whether, following implementation of Solvency II, a rating of a reinsurance company's financial strength should be published by its group supervisor. Since under Solvency II supervisory authorities will be in possession of capital adequacy ratios based on reinsurers' internal risk models, they will have information permitting them to assess realistically the financial strength of the companies they supervise. A regulatory rating of this kind could serve primarily as a basis for the calculation by primary insurers of the credit risk on a particular reinsurer. Given the potential that, in future, other jurisdictions will also require such calculations of their insurers, it would be expedient for the home-country regulator's rating to be recognised worldwide. The response of the CRO Forum to CEIOPS CP 16 takes up the idea of a regulatory rating and links it to mutual recognition of supervisory regulations through bilateral agreements (Article 50, RID). ${ }^{7}$

Where there is no regulatory rating, a conventional rating-agency rating could be used. ${ }^{8}$

There will probably be much discussion in Europe in the coming months on the supervisory requirements third-country reinsurers will need to fulfil under Solvency II to gain access to the European market. A system based on the "equivalence principle" would be desirable, though the question arises as to whether it could be implemented unilaterally or bilaterally. The answer may depend on the actual third-country jurisdiction concerned.

\section{Current situation - collateral/regulatory reform in the U.S.A.}

Discussions on reform of reinsurance supervision have been going on for years in the U.S.A. Two aspects are consistently the subject of criticism.

On the one hand, the fact that supervision does not take place at federal level, but at individual state level, naturally results in more administration for supraregional insurers, as they need a licence for every state in which they operate. This is particularly onerous for reinsurance companies with business models based on supraregional operations.

Secondly, some foreign reinsurers are unhappy with the requirement to provide "collateral" in the form, for example, of cash or letters of credit to secure liabilities to insurance companies domiciled in the U.S.A. These companies contend that this constitutes discrimination against foreign reinsurers, in that companies domiciled and licensed in the U.S.A. are not subject to these requirements.

\section{NAIC - Reinsurance Evaluation Office - December 2006 proposal}

The NAIC considered this criticism and at the end of 2006 decided to further evaluate a proposal for domestic and foreign reinsurance companies to be subject to the same obligations to provide collateral. This Reinsurance Evaluation Office (REO) proposal

\footnotetext{
${ }^{7}$ CRO Forum (2007). See Current Situation - collateral/regulatory reform in the U.S.A.

${ }^{8}$ Cf. German Insurance Association (2007).
} 
is designed to assess the financial strength and claims paying ability of reinsurers. The proposed system would function in the following way:

- The REO first would consider the ratings issued by the commercial rating agencies on reinsurance companies. Reference would be made explicitly to the ratings of all four main agencies and, depending on the rating level, a reduction in collateral down to 20 per cent would be possible (e.g. S\&P AA rating: reduction of 20 per cent; A rating: 50 per cent). In the event of conflicting ratings, the lowest would be applied.

- Evaluation of the supervisory systems of the countries in which reinsurers are domiciled would be based on IMF assessments.

- In addition, reinsurance companies would be subject to extensive application and reporting requirements, with the REO being empowered to request virtually any information it deemed appropriate from an applicant reinsurer.

- The REO also would be authorised to establish standards and require reinsurers to submit examination of their claim paying practices.

- Annual reports submitted would have to be adapted to U.S. GAAP.

- A fee would be payable by the applicant.

- An additional requirement for obtaining a reduction in collateral would be that the applicant would have to agree to be subject to U.S. jurisdiction.

The REO proposal should be rejected, since the requirements it imposes would give rise to a non-governmental body (the REO) performing what are essentially governmental/regulatory responsibilities. Additionally, the processes required by the REO would significantly increase bureaucracy and administrative requirements applicable both to U.S. and to non-U.S. reinsurers. The REO would de facto duplicate supervision of both U.S. and non-U.S. reinsurance groups, by requiring compliance with numerous requirements. For example, third-country reinsurers would have to submit reports complying with U.S. GAAP and undertake to provide all information considered necessary by the REO. Furthermore, it is planned to set up a database containing details of the time taken to settle reinsurance claims (prompt payment). ${ }^{9}$ However, it is questionable whether such a criterion is relevant for a business-to-business enterprise such as that operated by reinsurers. It should be the responsibility of professional insurers, which do not require the same protection as that afforded to consumers, and not that of a supervisory authority, to select reinsurance companies that are sufficiently solid. It is an essential component of good risk management that insurers undertake this task themselves, rather than rely on others. If proposals similar to the REO also found support elsewhere, reinsurers with international operations could face a "compliance nightmare".

In summary, the proposal under consideration by the NAIC Reinsurance Task Force to set up a $\mathrm{REO}^{10}$ simply disregards the fact that there are supervisory regimes

\footnotetext{
${ }^{9}$ The REO proposal provides: "The reinsurer's reputation for prompt payment of valid claims under reinsurance agreements, including the proportion of the reinsurer's obligations that are more than 90 days past due or are in dispute, including receivables payable to companies that are in Administrative Supervision or Receivership."

${ }^{10}$ Cf. proposal by the NAIC Reinsurance Task Force ( 2006).
} 
outside the U.S.A. that are comparable in their effectiveness, while probably using fewer resources. Were the U.S. insurance regulators able to evaluate and recognise other equivalent supervisory systems (such as the European supervisory system) there would be no need for collateral.

Optional Federal Charter/Nonadmitted and Reinsurance Reform Act of 2007 (H.R. 1065) In comparison with the NAIC REO approach there are a number of alternatives in the U.S.A., which propose a supervisory structure at the federal level, for example the proposal for an Optional Federal Charter (OFC). This provides for an option to either be regulated by the federal government or remain in the state system. This concept was introduced by the National Insurance Act of 2006 during the 109th Congress by the U.S. Senate and the U.S. House of Representatives. ${ }^{11}$ The National Insurance Act of 2006 would create a federal regulator, the "Office of National Insurance" (ONI), that would be located within the Department of Treasury and headed by a commissioner appointed by the President and subject to confirmation by the Senate. It is important to note that federal regulation by the ONI would be optional and that the state regulatory system would be retained for companies wishing to continue with that system. The OFC would not add another layer of regulation to the existing rules, but would establish an alternative regime to the existing state-based system. Once a company had become federally licensed, most relevant state laws and rules would be preempted, meaning that with a federal licence a reinsurer could transact reinsurance business in all U.S. insurance jurisdictions.

The Nonadmitted and Reinsurance Reform Act of 2007 (H.R. 1065) is substantially similar to the Nonadmitted and Reinsurance Reform Act of 2006 (H.R. 5637). H.R. 1065 was basically introduced to "streamline the regulation of nonadmitted insurance and reinsurance...". It seeks to modernise state regulation by designating a single state to exercise regulatory jurisdiction over certain aspects of any transaction involving surplus lines insurance and reinsurance. It uses the federal preemption authority to preclude other states from regulating in the specified areas. For example, H.R. 1065 would require that treatment of "credit for reinsurance" be governed by the ceding insurer's state of domicile, while the reinsurer's state of domicile would have sole authority to oversee its financial solvency. In contrast to the OFC, the federal government would not play a major role. In essence, H.R. 1065 would resemble in many respects the EU "lead supervisor" concept as introduced by the EU Insurance and Reinsurance Directives, as the state regulator concerned assumes sole responsibility for financial supervision.

These federal initiatives are to be welcomed, as they provide for a considerably more harmonised supervisory landscape. There are obvious similarities to U.S. banking supervision, which provides the option of regulation at either state or federal level.

${ }^{11}$ The National Insurance Act is expected to be reintroduced into the 110th Congress. In their 2007 report “Sustaining New York's and the U.S.'s Global Financial Services Leadership", New York City Mayor Michael Bloomberg and U.S. Senator Charles Schumer (D-N.Y.) express their support for an OFC as an approach that will improve regulatory efficiency and, in turn, the overall competitiveness of U.S. financial services institutions. 
A further advantage of the OFC proposal is that, to the extent insurance supervision becomes a federal responsibility, it will take place at that level of government which, in accordance with U.S. constitutional law, conducts foreign policy and concludes treaties with other countries. In this way, the OFC would pave the way for a more harmonised international regulatory structure founded on international agreements. ${ }^{12}$

\section{Emerging markets}

There are also legal and practical restrictions on access to commercially promising emerging markets, such as the BRIC countries ${ }^{13}$ and Mexico. These result from both measures affecting commerce as a whole and legal measures specific to insurers, together with bureaucratic procedures and soft constraints arising from culture, religion, history, politics and social norms. Many countries impose restrictions on foreigners, limiting the movement of natural persons. ${ }^{14}$ There are many restrictions on the type of presence allowed, illustrated by the following examples. Restrictions on foreign investment are common. For instance, in many countries, sole proprietorship is prohibited for foreigners or foreign direct investment is capped at a certain percentage (e.g. 50 per cent). In India, there is an equity cap of 26 per cent on insurance ownership. Similar capital restrictions apply to joint ventures. Finally, direct branches can also pose a problem, because either branches are not permitted at all, capital requirements are higher for foreign than for domestic companies, or the granting of licences for branches is subject to long delays. Even though such restrictions do not affect the insurance sector specifically, they are particularly onerous for reinsurers, since, as already mentioned, their business models are based on a worldwide spread of risks, and thus on worldwide access to markets. A consequence of such restrictions for reinsurers can be that the world market becomes so fragmented that business either becomes considerably more difficult or no longer appears worthwhile at all. ${ }^{15}$ This is most in evidence where restrictions apply specifically to insurance. In some jurisdictions for example, the regulator may set policy wordings, liability limits, clauses and extensions, or insurance cover from abroad or insurance

${ }^{12}$ See the next section entitled "What is to be done?"

13 Brazil, Russia, India and China.

${ }^{14}$ Employment is subject to the following restrictions in the BRIC countries: Brazil: Entry only permitted for highly qualified professionals and specialised technicians - if no nationals available; may not account for more than one in three workers; directors and managers - if vacancy, proof of need; not clear whether business visitors included, or contractual services covered. China: Entry only permitted for managers, executives and specialists as senior employees of branches, subsidiaries and representative offices as intra-corporate transferees (up to 3 years)/foreign-invested enterprises (for length of contract, up to 3 years)/business visitors (for 90 days) (not to create establishment). Contractual services not covered. India: Entry only permitted for managers, executives and specialists transferred to a branch or representative office/professional employees to render services under a contract (i.e. self-employed not covered)/business visitors (for 90 days)/repatriation of earnings not permitted. Mexico: Entry only permitted for managers, executives and specialists transferred within the same enterprise.

15 There are, however, a number of contrary trends - new technology and increasing globalisation/global clients/emergence of similar risks around the globe/global and national business conditions/concentration and transnational companies/incursion of other players competing with insurers/tighter integration of world financial markets. 
asset management may not be permitted, or there may be an obligation to offer a minimum of 50 per cent of the reinsurance requirement to local reinsurers. Supervisory authorities are increasingly requiring reinsurers to conduct their business through a subsidiary rather than a branch. There are also nationality requirements for managing directors and finance directors.

To summarise, world free trade has become so restricted in many regions that the European Commission is planning to create a "market access team". This team will be responsible for collecting trade information and identifying competitive disadvantages for European firms, and detecting protectionist tendencies, such as unfair customs procedures, tax systems, technical standards, hygiene and health regulations, copyright infringements, service restrictions and barriers to investment. ${ }^{16}$

\section{What is to be done?}

\section{European Union}

In the EU, the RID has brought reinsurance supervision close to that pertaining in a single market. ${ }^{17} \mathrm{~A}$ further step towards integration could be taken by extending the principle of mutual recognition beyond financial supervision to "governance requirements". The "fit and proper" control of senior management and shareholder control could be transferred to the home-country supervisory authority, simplifying administration for companies operating in a number of countries. The information requirements of the supervisory authorities in the countries of operation could be satisfied by information exchange among regulators.

There is a need for action in respect of insurance and reinsurance groups with subsidiaries in other EU countries, as the RID only applies the principle of mutual recognition to a head office and branches situated in the EU, and excludes subsidiaries. ${ }^{18}$ This appears inappropriate, bearing in mind that large groups operating supraregionally need to manage their business and risks on that basis. Indeed, modern international risk management and control systems adapted to worldwide business activity are frequently in use throughout the large insurance and reinsurance groups. They are used not only to manage the liabilities in the balance sheet, but are just as important for managing the assets and the correlations between the two. Painful experiences, particularly in 2001/2002 following the simultaneous occurrence of extreme losses (WTC) and turbulence in the capital markets, have led companies to analyse risks on both the asset and the liability sides of the balance sheet even more closely and to get better at identifying potential risk accumulations. The growing importance of asset-liability management and control of risk concentration are evidence of this. For example, the Munich Re Group identifies risk concentrations

\footnotetext{
${ }^{16}$ Financial Times Deutschland (2007, p. 1).

${ }^{17}$ See the sub-section entitled "Current situation - supervision following the Reinsurance Directive".

${ }^{18}$ While the Directive on Insurance Groups (source) considers groups as a whole, it is separate from and complementary to the RID, the provisions of which must also be complied with.
} 
within each business line as well as across risk categories. At Group level, all relevant exposures are captured and monitored within the context of strategic risk management. This top-down approach is then broken down by major divisional unit or legal entity.

The subject of financial supervision is thus regularly on the agenda at Group senior management level, where the threads are brought together and decisions taken. It would therefore be more consistent for supervisory authorities to align their procedures with the control and risk-management structures of the companies they are regulating. Only by doing so will it be possible to ensure efficient supervision.

To this end, the European Financial Services Round Table (EFR) proposed that supervision of large groups be transferred to a lead supervisor, which would basically be responsible for the entire financial supervision of a group, in close cooperation with local supervisory authorities. ${ }^{19}$ The authorities themselves are also looking at this type of approach. The FSA and HM Treasury (U.K.) have submitted a proposal for "Supervising Insurance Groups under Solvency II", 20 according to which parent companies of EU insurance groups would have to fulfil the solvency capital requirement (SCR, i.e. target capital), while subsidiaries would be obliged only to maintain the minimum capital requirement (MCR), enabling the benefits of diversification to be exploited. A solution to the problem along these lines will doubtless also depend on what form of contingent capital support by the parent company for the difference between the SCR and the MCR is prescribed.

\section{Bilateral agreements on the supervision of reinsurance companies}

International agreements on reinsurance company supervision are a good way of ensuring market access for reinsurers in as many countries as possible and achieving an efficient supervisory structure. In Europe, a legal basis is provided by Article 50 of the RID.

According to Article 50, the European Commission may submit proposals to the Council for the negotiation of agreements with one or more third countries on market access and the means of exercising supervision over reinsurance companies. Essentially, it concerns transferring responsibility for supervision on the basis of mutual recognition. If two jurisdictions recognise their respective supervisory systems as having "equal" status, the host supervisory authority may waive its right to financial supervision in favour of the home state supervisory authority.

To take account of the justifiable concern of supervisory authorities in countries of operation of reinsurers that they should receive information on the security of companies, bilateral agreements could also include provisions relating to the exchange of information between supervisory authorities.

\footnotetext{
${ }^{19} \mathrm{Cf}$. www.efr.be.

${ }^{20} \mathrm{Cf}$. http://www.fsa.gov.uk/pubs/international/dp_solvency.pdf.
} 


\section{Free-trade agreements/partnership agreements}

In many cases, as an alternative to concluding separate agreements on market access for and supervision of reinsurers, it will be appropriate to incorporate a special provision covering these issues in existing or new free-trade agreements. This would also apply to partnership agreements, for which the EU is likewise responsible.

A special clause along the following lines could be used:

\section{Authorisation and Supervision of Reinsurance Business}

1. Commencement of reinsurance business shall be subject to prior official authorisation by the competent authorities of the member state in the territory of which the reinsurance undertaking establishes its head office.

2. The financial supervision of an authorised reinsurance undertaking, including that of the business it conducts either through branches or through cross-border business, shall be the sole responsibility of the member state in which its head office is located.

3. Financial supervision pursuant to paragraph 2 shall include verification, with respect to the reinsurance undertaking's entire business, of its state of solvency, of the establishment of technical provisions and of the assets covering them in accordance with the rules laid down or practices followed in the home state.

4. The member states shall provide that all persons working or who have worked for the competent authorities, as well as auditors and experts acting on behalf of the competent authorities, are bound by an obligation of professional secrecy.

5. Paragraph 4 shall not prevent the competent authorities of the different member states from exchanging information in the discharge of their supervisory functions.

6. Competent authorities receiving confidential information under paragraphs 4 and 5 may use it only in the course of their duties:

(a) to check that the conditions governing the commencement of the business of reinsurance are met and to facilitate monitoring of the conduct of such business, especially with regard to the monitoring of technical provisions, solvency margins, administrative and accounting procedures and internal control mechanisms,

(b) to impose penalties,

(c) in administrative appeals against decisions of the competent authorities or

(d) in court proceedings.

\section{IAIS (International Association of Insurance Supervisors) activities}

\section{"Issues paper" on mutual recognition}

The "Mutual Recognition Subgroup" at the IAIS, a working group of the Reinsurance Subcommittee, has already started work on issues relating to the mutual recognition of supervisory regulations. The intention of the IAIS Mutual Recognition Subgroup is to produce a checklist to be used for verifying whether supervisory regulations fulfil certain minimum requirements. In line with Article 50, the objective is the conclusion of international agreements on the supervision of reinsurance companies. This work is very much in the interest of reinsurance companies with 
worldwide operations, but, unfortunately, completion of the report, which will probably be in the form of a "guidance paper", has been delayed repeatedly due to other, more pressing IAIS work. An "issues paper", to be produced in the course of this year, was first discussed at the last meeting of the IAIS Mutual Recognition Subgroup in Dubai in February 2007. The issues paper could list the points to be considered by supervisory authorities before they enter into negotiations on mutual agreements. A discussion paper of this kind would be an important first step towards fulfilling the mission of the IAIS Mutual Recognition Group. ${ }^{21}$ It would be very positive if, after 3 years' work, the IAIS succeeded in producing such a paper in time for the Annual General Meeting of the IAIS in October $2007 .^{22}$

Model MMoU (multilateral memorandum of understanding on cooperation and information exchange among regulators)

Cooperation between regulators in day-to-day supervision would be much improved by the creation of a relationship of mutual trust. The Model MMoU recently issued by the IAIS constitutes a first step. ${ }^{23}$ The MMoU defines in particular the practical arrangements concerning cross-border cooperation and information exchange and confidentiality issues. The IAIS considers the MMoU essential not only in crisis situations, but also in insurance industry supervisors' day-to-day business, especially given their significant role in preserving financial stability.

Until the IAIS MMoU was formally approved by the responsible bodies in February 2007, the insurance sector had expressed its concern that insurers subject to requests for exchange of information would not be formally notified of such requests and the possible flow of information. The basis of this concern was that, in large companies, it would be extremely difficult to keep track of all business unit contacts with regulators worldwide, and information asymmetry could in some cases result in regulatory complications. The IAIS has attempted to address these concerns essentially by maintaining that information exchange among regulators already takes place and that the new MMoU merely constitutes a written agreement on the process. Given that few supervisors have responded negatively, it will be interesting to see how many, and which, countries agree to sign the MMoU.

${ }^{21}$ IAIS quote: "The mission of the Reinsurance Mutual Recognition Subgroup of the Reinsurance and Other Forms of Risk Transfer Subcommittee is to facilitate reinsurance by developing an efficient and effective international supervisory framework. The framework should be sufficient to allow (host) supervisors to mutually recognise the quality of the regulation and supervision exercised by supervisors in another (home) jurisdiction, and thus possibly remove or alleviate additional regulatory and supervisory requirements for reinsurers in that host jurisdiction. To this end, the Subgroup should identify the minimum principles for the essential coordination of reinsurance regulation and supervision in a jurisdiction sufficient to allow mutual recognition and thereby further strengthen cooperation and trust between reinsurance supervisors, both on a bi-lateral and a multi-lateral basis".

${ }^{22}$ The first meeting of the IAIS mutual Recognition Subgroup took place in Amman, Jordan on 4 October 2004.

${ }^{23}$ The IAIS MMoU approved in Dubai in February 2007 defines the formal basis for the ongoing exchange of information among regulators. 


\section{Conclusion}

In the European Union, the regulations required to create a single market in reinsurance are essentially in place. Free market access, freedom of contract, full fungibility of capital and a level playing field are guaranteed, and the risk of regulatory arbitrage has been eliminated. It would be desirable for this system to be extended to other countries outside the European Union, both to increase the efficiency of supervision and to facilitate the worldwide operation of reinsurance companies, not least with the aim of rendering insurable natural catastrophe risks and risks relating to technical innovations, which would otherwise be uninsurable or insurable only at considerably higher cost.

\section{References}

CRO Forum (2007) CRO Forum Response to CP 16, available at http://www.croforum.org/home.ecp, January.

EU Council of Ministers (2005) Directive 2005/68/EC of the European Parliament of the Council of 16 November 2005 on reinsurance and amending Council Directives 73/239/EEC 92/49/EEC as well as Directives 98/78/EC and 2002/83/EC, Brussels: EU Council of Ministers, 16 November.

Evans, A. (2007) 'The EU Reinsurance Directive', The Geneva Papers on Risk and Insurance - Issues and Practice 32: 95-104.

Financial Times Deutschland (2007) 'EU will Handelspolizei gründen', Financial Times Deutschland, 18 April, p. 1.

German Insurance Association (2007) Solvency II and Reinsurance, Discussion Paper, German Insurance Association, available at www.gdv.de.

NAIC Reinsurance Task Force (2006) Reinsurance Evaluation Office - Proposal to Grant Credit for Ceded Reinsurance, available at www.naic.org/committees_e_reinsurance.htm.

\section{About the Authors}

Ralph Vogelgesang is Chief Legal Officer, Munich Re, Munich.

Matthias Kubicek is Legal Counsel, Munich Re, Munich. 